\title{
Current state of emergency medicine in Fukushima 4 years after the Great East Japan Earthquake
}

\author{
Yukihiro Ikegami, ${ }^{1,2}$ Shinichi Konno, ${ }^{2}$ Tsuyoshi Isosu, ${ }^{1}$ Shinju Obara, ${ }^{1}$ \\ Takahiro Hakozaki, ${ }^{1}$ Masahiko Akatsu, ${ }^{2}$ Masahiro Murakawa ${ }^{1}$
}

On 11 March 2011, a huge tsunami exceeding $13 \mathrm{~m}$ in height generated by the Great East Japan Earthquake widely damaged the Pacific coastal area of Fukushima Prefecture. The tsunami induced loss of the power supply to nuclear reactors 1-4 at the Fukushima Daiichi Nuclear Power Plant (see figure 1; F1 on map). Steam explosions of the reactor buildings ensued, and the eastern part of Fukushima Prefecture was widely contaminated by scattered radioactive materials. At that time, we were engaged in the forefront of emergency medical care at Fukushima Medical University Hospital for the victims of this disaster. Fukushima Prefecture has two nuclear power plants, and we had prepared for radiation accidents before the Great East Japan Earthquake. We learned how to measure radiation activity and decontaminate radioactive materials. However, these actions were not useful for this disaster because our training involved learning how to treat only two to three patients involved in radiation accidents in nuclear power plants. We were thus unprepared for this large-scale disaster. The most urgent problem for us was the sudden closing of hospitals around F1. We had to accept large numbers of patients from these hospitals, and many of the patients were transported with only the clothes on their backs. Because the communication system in Fukushima Prefecture completely collapsed, dozens of patients were transported by the Japan Self-Defense Force and arrived at our hospital without any information. These patients required radioactivity screening, but we could not take rapid action because of the lack of trained staff members and danger involved in handling radioactivity measuring

\footnotetext{
${ }^{1}$ Department of Anesthesiology, School of Medicine, Fukushima Medical University, Fukushima, Japan; ${ }^{2}$ Department of Disaster and Comprehensive Medicine, School of Medicine, Fukushima Medical University, Fukushima, Japan

Correspondence to Dr Yukihiro Ikegami, Department of Anesthesiology, School of Medicine, Fukushima Medical University, 1 Hikarigaoka, Fukushima 9601295, Japan;

yikegami@fmu.ac.jp
}

devices. In many cases, these patients had to undergo long-distance transfer to hospitals in other prefectures after temporarily staying in our hospital because we could not provide sufficient medical services.

Four years later, the area has not recovered. The Pacific coastal area of Fukushima includes (from north to south) the regions of Sōma, Futaba and Iwaki (see map). The Fukushima Daiichi Nuclear Power Plant is located in the Futaba area. The population dynamics data reported a year after the tsunami by Fukushima Prefecture in April 2012 showed remarkable movement of residents in the Pacific coastal area. These movements were most pronounced in the Futaba area, where more than 88000 people underwent compulsory evacuation. In Okuma town, where F1 is located, the population is estimated to have significantly decreased from 13000 to less than 10000 because residents were restricted from wide areas. However, the population in the Iwaki area actually increased because more than 20000 people had fled there from the Futaba area.

The medical field, particularly the emergency medical services (EMS), currently faces many serious problems in these areas. The outflow of medical staff has been considerable; therefore, many hospitals, including designated emergency hospitals, have been forced to close. There were originally six designated emergency hospitals in the Sōma area, but at present, three in the south of the region cannot receive emergency patients. The number of fulltime doctors has decreased by $30 \%$ and the number of nurses by $20 \%$. In the Futaba area, there were four designated emergency hospitals, but all of them closed after the disaster. The decrease in medical staffing has been severe: $80 \%$ of full-time doctors and $30 \%$ of nurses have left this area. Although 4 years have passed since the disaster, many of these doctors and nurses have not returned, and the hospitals are still suffering from a serious medical staff shortage.

Because the collapse of the patient assignment systems in the Sōma and Futaba areas is continuing even now, ambulance crews must often contact several hospitals simultaneously for admission requests until one hospital accepts. After the disaster, the number of emergency transports increased from the Sōma area to Miyagi Prefecture, located on the north side of Fukushima Prefecture. Many emergency patients from the Futaba area need to be transported to the Iwaki area because the closing of hospitals in the Futaba area is continuing. This has negatively impacted the EMS in the Iwaki area, reducing the acceptance rate of emergency patients living in the Iwaki area. Ambulance crews in the Futaba area have found that some hospitals in the Iwaki area rejected requests for admission because the medical staff feared radiation contamination. We are deeply concerned about the continuing dysfunction of hospitals in these areas because refusal of patient admission by hospitals induces serious prolongation of patient stays at hospital call points. For patients in very poor condition, delay of emergency treatment often leads to death.

It appears that a serious population decline is continuing even 4 years since the disaster. The number of patients younger than 19 years is significantly decreasing in the Sōma and Futaba areas. In the Futaba area, the total number of emergency patients transported by EMS is annually decreasing at a rapid rate. The ratio of women to men is also significantly decreasing. Ambulance crews are pointing out an increase in the number of older patients coming from temporary housing in the Sōma and Iwaki areas. Life in temporary housing is difficult, and we are concerned about the potential detrimental effects on these older patients' health. Many older patients living in temporary housing have chronic geriatric diseases, and the ambulance crews observe that such older people often stop medical treatments because they have been separated from their home towns. Even when ambulance crews suspect stroke or heart attack, these patients face delays in receiving effective treatment because it is difficult for crews to access important data from their clinical history.

Industrial accidents during decontamination work are dramatically increasing in every area, and many temporary labourers are coming to Fukushima from distant regions to earn money. They have no living base in Fukushima Prefecture and often face serious medical expenses because they do not have National Health Insurance. Consequently, the burden on medical institutes in Fukushima has increased in many cases.

We visited F1 for the first time in December 2011 after the radiation disaster. 


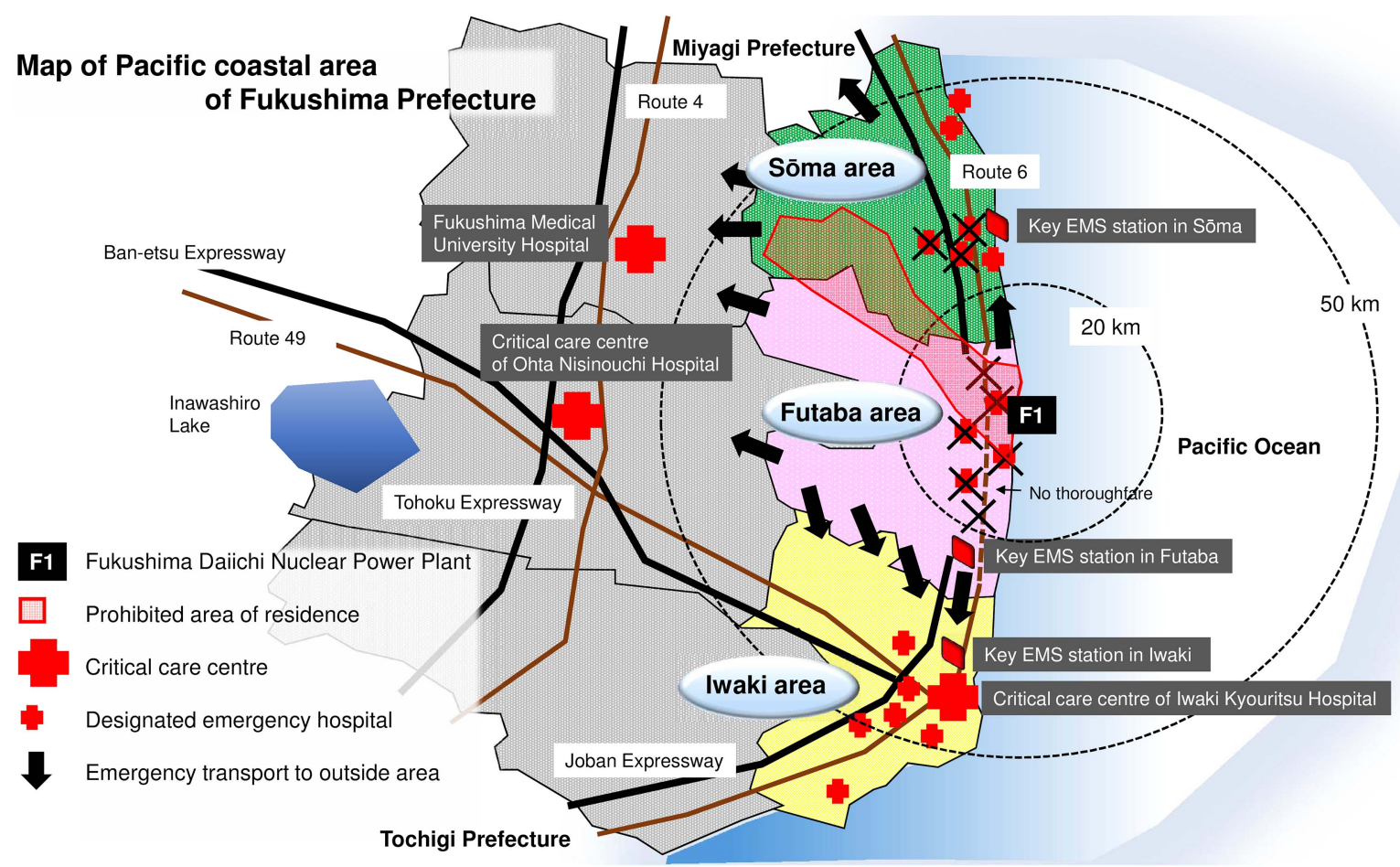

Figure 1 Map of Pacific coastal area of Fukushima Prefecture.
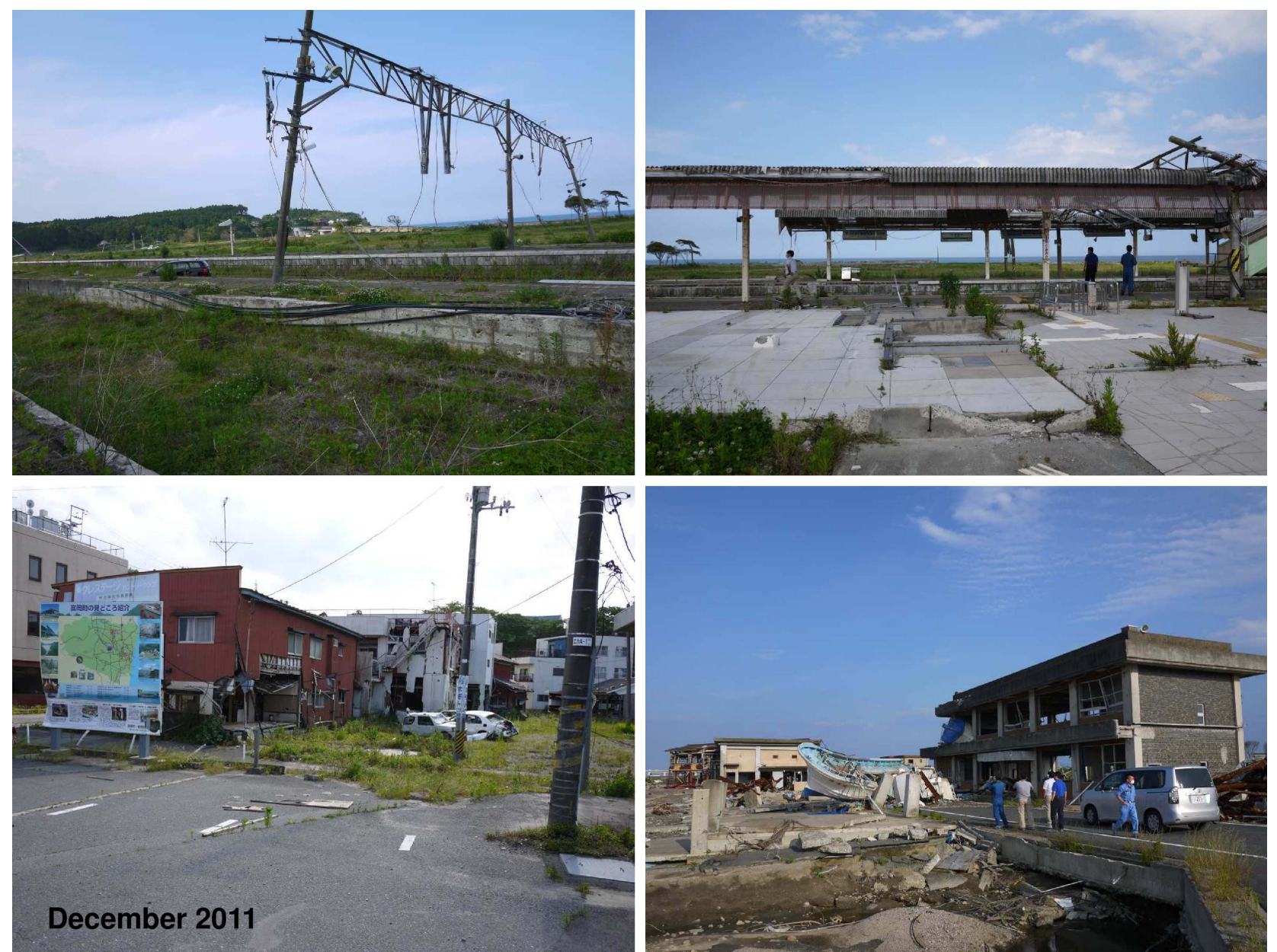

Figure 2 Photographs from December 2011. 
Many buildings around F1 were left in collapse after the earthquake. Telephone poles were inclined and the roads sank everywhere (see figure 2; photographs). We felt that the Futaba area had changed to a town of death. Contamination by radioactive materials destroys local communities. Young generations, particularly young mothers with children, are very concerned about radioactivity; they do not readily return to their hometown even if the level of radioactivity has decreased.

Unfortunately, it will take a very long time until the EMS in the Pacific coastal area of Fukushima Prefecture completely recovers. We anticipate re-establishment of the EMS in Fukushima Prefecture and hope that all of the evacuated residents can eventually return to their home towns. Although extremely slow, there are signs of recovery; namely, advances in radioactivity decontamination measures, road improvements and the return of a few young people to their hometowns with the lift of the evacuation order. We believe that reporting of such experiences is a valuable contribution to many emergency doctors worldwide. Finally, we deeply appreciate all of the health workers who generously provided help.

Contributors YI drafted the manuscript based on personal experiences and personally accumulated information. $\mathrm{TI}, \mathrm{SO}$ and $\mathrm{TH}$ are colleagues at Fukushima Medical University Hospital and devotedly committed to supporting emergency patients. SK and MA are working to restore and rebuild medical care and provided $\mathrm{YI}$ and colleagues with abundant support, enabling them to efficiently perform medical treatment. MM comprehensively assisted in refining the English in the manuscript. All authors contributed substantially to the manuscript's revision. All authors take responsibility for the document as a whole. Editorial assistance was provided by Edanz Group Ltd, a professional editing company.

Competing interests None.

Patient consent Obtained.

Ethics approval Ethics committee in Fukushima Medical University.

Provenance and peer review Not commissioned; internally peer reviewed.

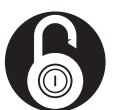

\section{OPEN ACCESS}

Open AccessThis is an Open Access article distributed in accordance with the Creative Commons Attribution Non Commercial (CC BY-NC 4.0) license, which permits others to distribute, remix, adapt, build upon this work non-commercially, and license their derivative works on different terms, provided the original work is properly cited and the use is non-commercial. See: http:// creativecommons.org/licenses/by-nc/4.0/

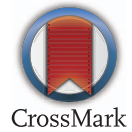

To cite Ikegami Y, Konno S, Isosu T, et al. Emerg Med J 2015;32:665-667.

Received 27 December 2014

Revised 22 February 2015

Accepted 26 February 2015

Published Online First 17 March 2015

Emerg Med J 2015:32:665-667.

doi:10.1136/emermed-2014-204622 